\title{
Prevalence and Characteristics of Pneumonitis Following Irradiation of Breast Cancer
}

\author{
ELISA M. WERNER ${ }^{1}$, MARIE C. EGGERT $^{1}$, SABINE BOHNET $^{2}$ and DIRK RADES ${ }^{1}$ \\ ${ }^{1}$ Department of Radiation Oncology, University of Lübeck, Lübeck, Germany; \\ ${ }^{2}$ Department of Pulmonology, University of Lübeck, Lübeck, Germany
}

\begin{abstract}
Background/Aim: Pneumonitis is a serious complication after radiotherapy of breast cancer. This study aimed to identify its prevalence and potential risk factors. Patients and Methods: A total of 606 patients irradiated following breast-conserving surgery or mastectomy were retrospectively analyzed. In patients developing pneumonitis, radiation and clinical parameters were investigated to identify potential risk factors. Results: Eleven patients $(1.8 \%)$ developed a pneumonitis grade $\geq 2$. Mean doses to the ipsilateral lung were $>7$ Gy in 5 patients (45\%). Of the other patients, 5 had a chronic inflammatory disease. Six patients (55\%) had another malignancy (4 previous contralateral breast cancers, 1 previous ovarian and thyroid cancer, 1 synchronous carcinoma-in-situ (pTis) at the contralateral breast). Five patients (45\%) received chemotherapy including taxanes and 4 patients (36\%) received trastuzumab. Conclusion: The prevalence of pneumonitis was $1.8 \%$. Potential risk factors included mean radiation dose to ipsilateral lung $>7 \mathrm{~Gy}$, systemic treatment with taxanes or trastuzumab, chronic inflammatory disease and history of another malignancy.
\end{abstract}

Breast cancer is the most common type of cancer in women in Europe and Northern America (1). Most patients with early-stage (T1- or T2-disease) tumors without lymph-node involvement receive breast conserving surgery followed by whole-breast irradiation (2). Patients with locally advanced cancer (T3- or T4-disease) generally receive mastectomy followed by radiotherapy of the chest wall. In case of involvement of axillary lymph nodes and presence of risk

Correspondence to: Prof. Dirk Rades, MD, Department of Radiation Oncology, University of Lübeck, Lübeck, Ratzeburger Allee 160, 23562 Lübeck, Germany. Tel: +49 45150045401, Fax: +49 45150045404, e-mail: dirk.rades@uksh.de

Key Words: Breast cancer, irradiation, pneumonitis. factors, regional lymph nodes may be included in the treatment volume after both breast-conserving surgery and mastectomy.

Radiotherapy of breast cancer is generally well tolerated with only minor toxicity such as erythema of the irradiated skin and fatigue. However, pneumonitis that may occur after several weeks following radiotherapy is a more serious sideeffect (3). In a systematic review including data from 1995 to 2014, the prevalence of pneumonitis after radiotherapy of breast cancer patients ranged between $0.8 \%$ and $2.9 \%$ (4). However, in a more recent retrospective study of 515 patients, the pneumonitis rate was $3.7 \%$, and in a prospective study, the rate of pneumonitis was $13 \%$ in patients who had received previous systemic treatment $(3,5)$. In order to define the current prevalence of pneumonitis after radiotherapy of breast cancer more precisely, additional studies of more recently treated patients are required. Therefore, we performed the present study in breast cancer patients irradiated between 2016 and 2019.

\section{Patients and Methods}

A total number of 606 female breast cancer patients who received radiotherapy following breast conserving surgery or mastectomy between January 2016 and May 2019 were retrospectively evaluated for radiation pneumonitis grade $\geq 2$. This evaluation included patients who received postoperative irradiation to the whole-breast or the chest wall (plus/minus a boost to the tumor bed) with or without irradiation to supraclavicular plus/minus internal mammary lymph nodes. In patients who experienced pneumonitis, radiation and other clinical parameters were investigated to identify potential risk factors for the development of radiation pneumonitis. Radiation parameters included the treatment volume (whole-breast or chest wall plus/minus supraclavicular/internal mammary lymph nodes), administration of a radiation boost, prescribed radiation doses and dose-fractionation regimens, mean radiation doses to the ipsilateral lung, and use of the deep-inspiration breath hold (DIBH) technique. Clinical parameters included age at radiotherapy, tumor stage, histologic grading, estrogen and progesterone receptor status, HER-2 (human epidermal growth factor 2)/neu receptor status, relevant comorbidity and type of systemic treatment. 
Table I. Radiation parameters of the 11 patients who developed pneumonitis.

\begin{tabular}{|c|c|c|c|c|c|}
\hline Patient number & Treatment volume & Radiation dose & Boost to tumor bed & DIBH technique & Mean dose to ipsilateral lung \\
\hline 1 & Whole breast (right side) & $50.4 \mathrm{~Gy}(28 \times 1.8 \mathrm{~Gy})$ & $5 \times 2.0 \mathrm{~Gy}$ (sequential) & Yes & $6.4 \mathrm{~Gy}$ \\
\hline 2 & Whole breast (left side) & $50.4 \mathrm{~Gy}(28 \times 1.8 \mathrm{~Gy})$ & $28 \times 0.3 \mathrm{~Gy}(\mathrm{SIB})$ & Yes & $9.8 \mathrm{~Gy}$ \\
\hline 3 & Whole breast (left side) & $50.4 \mathrm{~Gy}(28 \times 1.8 \mathrm{~Gy})$ & $5 \times 2.0 \mathrm{~Gy}$ (sequential) & Yes & $8.3 \mathrm{~Gy}$ \\
\hline 4 & Whole breast (left side) & $50.4 \mathrm{~Gy}(28 \times 1.8 \mathrm{~Gy})$ & No & Yes & $7.7 \mathrm{~Gy}$ \\
\hline 5 & Whole breast (right side) & $50.4 \mathrm{~Gy}(28 \times 1.8 \mathrm{~Gy})$ & $5 \times 2.0 \mathrm{~Gy}$ (sequential) & No & $11.2 \mathrm{~Gy}$ \\
\hline 6 & Whole breast (left side) & $40.0 \mathrm{~Gy}(15 \times 2.667)$ & $5 \times 2.0 \mathrm{~Gy}$ (sequential) & Yes & $4.3 \mathrm{~Gy}$ \\
\hline 7 & Right chest wall + lymph nodes* & $50.4 \mathrm{~Gy}(28 \times 1.8 \mathrm{~Gy})$ & No & No & $15.5 \mathrm{~Gy}$ \\
\hline 8 & Whole breast (bilateral) & $40.0 \mathrm{~Gy}(15 \times 2.667)$ & No & No & $\begin{array}{l}\text { 6.9Gy (right side) } \\
6.0 \mathrm{~Gy} \text { (left side) }\end{array}$ \\
\hline 9 & Whole breast (right side) & $29.3 \mathrm{~Gy} * *(11 \times 2.667)$ & No & Yes & $4.0 \mathrm{~Gy}$ \\
\hline 10 & Whole breast (right side) & 40.0Gy $(15 \times 2.667)$ & $5 \times 2.0 \mathrm{~Gy}$ (sequential) & No & $6.8 \mathrm{~Gy}$ \\
\hline 11 & Whole breast (right side) & $40.0 \mathrm{~Gy}(15 \times 2.667)$ & No & Yes & $4.1 \mathrm{~Gy}$ \\
\hline
\end{tabular}

DIBH: Deep inspiration breath hold; SIB: simultaneous integrated boost. *Supraclavicular and internal mammary lymph nodes; **Radiotherapy stopped due to pneumonitis (planned dose: 40 Gy without boost).

\section{Results}

Eleven patients (1.8\%) were identified in the entire cohort of 606 patients who developed a pneumonitis grade $\geq 2$ during or after radiotherapy of breast cancer. Pneumonitis was diagnosed after a median of 7.5 weeks (range $=0-19$ weeks) following radiotherapy.

All patients presented with progressive cough; 8 patients complained about dyspnea, and 3 patients had fever. All patients received prednisolone for up to 13 weeks, and pneumonitis resolved without sequelae in 9 patients. One patient required a second course of prednisolone (12 weeks), before resolution of pneumonitis resolved, and one patient still complained about dry cough and exertional dyspnea at 22 months following radiotherapy.

Of the 11 patients, 10 received whole-breast radiotherapy alone (plus a boost to the tumor bed in 6 patients) following breast conserving surgery ( 9 unilateral, 1 bilateral), and one patient received irradiation of the chest wall plus supraclavicular and internal mammary lymph nodes without a boost. The DIBH technique was used in 7 patients.

According to the Quantitative Analyses of Normal Tissue Effects in the Clinic (QUANTEC), a mean lung dose of 7 Gy is associated with a $5 \%$-risk of symptomatic (i.e. grade $\geq 2$ ) radiation pneumonitis (6). In the present study, the mean dose to the ipsilateral lung was $>7$ Gy in 5 patients $(7.7,8.3$, 9.8, 11.2 and $15.5 \mathrm{~Gy})$. Of the other 6 patients, 5 patients had a chronic inflammatory disease (bronchial asthma $n=2$, rheumatoid arthritis $n=2$, rheumatoid arthritis plus Crohn's disease $n=1$ ).

Four of the 11 patients (36\%) had previous contralateral breast cancer, one patient (9\%) previous ovarian and thyroid cancer, and one patient (9\%) synchronous carcinoma-in-situ (pTis) of the contralateral breast. The median age of the 11 patients developing pneumonitis was 59 years (range $=43-80$ years). None of the patients had a smoking history. All patients received systemic treatment prior or during radiotherapy. Five patients $(45 \%)$ received chemotherapy including taxanes. Four patients (36\%) received trastuzumab in addition to chemotherapy, which was combined with pertuzumab in 2 patients (18\%).

Additional radiation parameters are summarized in Table I. Administered systemic treatments, tumor stages and histologic parameters are given in Table II.

\section{Discussion}

Many breast cancer patients receive radiotherapy. Since breast cancer is one of the most common cancers worldwide, a lot of research is performed in order to improve the outcomes after radiotherapy for the primary tumor and metastatic disease (7-13). Pneumonitis can be a serious complication of radiotherapy of malignancies within or adjacent to the thorax such as breast cancer, lung cancer and esophageal cancer.

Severe radiation pneumonitis has been reported to have a negative impact on the survival of patients irradiated for lung cancer (14). Pneumonitis after radiotherapy of breast cancer is less common than after radiotherapy of lung cancer. In most studies, pneumonitis rates in irradiated breast cancer patients were less than $3 \%$ (4). However, in a retrospective study of 515 irradiated breast cancer patients published in $2017,3.7 \%$ $(n=19)$ of the patients developed grade 2 radiation pneumonitis (5). In that study, the risk of pneumonitis was associated with the radiation dose to the ipsilateral lung. This agrees well with the findings of our present study, where the mean dose to the ipsilateral lung was $>7 \mathrm{~Gy}$ in 5 of the patients (45\%), which is generally considered to be associated with a pneumonitis risk of 5\% (6). In 2004, a prospective study of 524 breast cancer patients compared chemotherapy with four cycles of paclitaxel followed by four cycles of 5- 
Table II. Systemic treatments, tumor stages and histologic parameters of the 11 patients who developed pneumonitis.

\begin{tabular}{|c|c|c|c|c|c|c|c|}
\hline Patient number & Chemotherapy & $\begin{array}{c}\text { Other systemic } \\
\text { treatment }\end{array}$ & Tumor stage & $\begin{array}{c}\text { Histology, } \\
\text { Grading }\end{array}$ & $\begin{array}{c}\mathrm{ER} / \mathrm{PR} \\
\text { status }\end{array}$ & $\begin{array}{c}H E R-2 / n e u \text { receptor } \\
\text { status }\end{array}$ & $\begin{array}{c}K i-67 \text { labeling } \\
\text { index }\end{array}$ \\
\hline 1 & $\begin{array}{l}\text { 6×Doc/Carbo } \\
\text { (neoadjuvant) }\end{array}$ & $\begin{array}{l}\text { TRA/PER } \\
\text { Letrozol }\end{array}$ & $\begin{array}{c}\text { cT2 cNx } \\
\text { ypT0 ypN0 }\end{array}$ & NST, G3 & $12 / 12$ & Positive & $70 \%$ \\
\hline 2 & $\begin{array}{l}4 \times \mathrm{EC} / 12 \times \mathrm{Pac} \\
\text { (neoadjuvant) }\end{array}$ & $\begin{array}{l}\text { TRA/PER } \\
\text { Tamoxifen }\end{array}$ & $\begin{array}{l}\text { cT1 } \mathrm{cN}+ \\
\text { ypT0 ypN0 }\end{array}$ & NST, G3 & $12 / 8$ & Positive & $15 \%$ \\
\hline 3 & $\begin{array}{c}12 \times \mathrm{Pac} \\
\text { (adjuvant) }\end{array}$ & $\begin{array}{c}\text { TRA } \\
\text { Tamoxifen }\end{array}$ & pT1b pN0 & Lobular, G2 & $3 / 2$ & Positive & $5 \%$ \\
\hline 4 & No & Letrozol & pT1b pN0 & NST, G1 & $+/+$ & Negative & $5 \%$ \\
\hline 5 & No & Letrozol & pT1c pNo & NST, G2 & $12 / 0$ & Negative & $10 \%$ \\
\hline 6 & No & Tamoxifen & pT1b pN0 & NST, G1 & $9 / 12$ & Negative & $5 \%$ \\
\hline 7 & $\begin{array}{c}4 \times \mathrm{EC} / 12 \times \mathrm{Pac} \\
\text { (adjuvant) }\end{array}$ & Tamoxifen & pT3 pN1a & NST, G3 & $12 / 1$ & Negative & $17 \%$ \\
\hline 8 & No & Tamoxifen & $\begin{array}{l}\text { pT1 pN0 (R) } \\
\text { pTis (L) }\end{array}$ & $\begin{array}{l}\text { NST, G2 } \\
\text { G3 }\end{array}$ & $12 / 6$ & Negative & $6 \%$ \\
\hline 9 & $\begin{array}{c}12 \times \text { Pac } \\
\text { (adjuvant) }\end{array}$ & $\begin{array}{l}\text { TRA* } \\
\text { Letrozol }\end{array}$ & pT1b pN0 & NST, G3 & $12 / 0$ & Positive & $15 \%$ \\
\hline 10 & No & Tamoxifen & pT1a pN0 & NST, G3 & $12 / 2$ & Negative & $12 \%$ \\
\hline 11 & No & Tamoxifen & pT1b pN0 & NST, G1 & $12 / 6$ & Negative & $5 \%$ \\
\hline
\end{tabular}

ER: Estrogen receptor; PR: progesterone receptor; HER-2: human epidermal growth factor 2; Doc: docetaxel; Carbo: carboplatin; TRA: trastuzumab; PER: pertuzumab; NST: no special type; EC: epirubicin/cyclophopsphamide; Pac: paclitaxel; (R): right side; (L): left side. *Trastuzumab stopped due to pneumonitis.

fluorouracil (5-FU), doxorubicin and cyclophosphamide (FAC) to 8 cycles of FAC (15). In that study, data of 189 patients (100 and 89 patients, respectively) receiving subsequent radiotherapy were available. Of these patients, $5 \%$ in the paclitaxel-FAC group and $4.5 \%$ in the FAC group, respectively, developed a clinically relevant pneumonitis. Moreover, taxanes have the potential to increase the risk of radiation pneumonitis and even to introduce pneumonitis independently of radiotherapy $(3,15-17)$. In the present study, 5 patients $(45 \%)$ had received chemotherapy including taxanes. Trastuzumab, which was received by 4 patients $(36 \%)$ in the present study, has also been reported to have the potential to lead to interstitial pneumonitis (18).

In addition to factors that are known to increase the risk of radiation pneumonitis, chronic inflammatory disease, namely bronchial asthma or rheumatoid arthritis, was present in $45 \%$ of our patients and, therefore, may be a risk factor for developing pneumonitis. Bronchial asthma is a chronic inflammatory disease of the lung, and rheumatoid arthritis may also affect the lungs $(19,20)$. Moreover, $55 \%$ of the patients in our study who developed pneumonitis had a history of another malignancy. One may speculate that these patients had a reduced DNA repair capacity, which has been described for several tumor entities (21-23). In addition, a study from Italy that compared 43 breast cancer patients to 34 healthy controls has suggested that breast cancer was associated with an impairment of the DNA repair capacity resulting in an increased radio-sensitivity and radiation toxicity (24). The results of these studies support the idea that patients with a history of an additional malignancy have reduced DNA repair capacity and a higher risk of developing radiation pneumonitis.

In summary, the prevalence of pneumonitis in this cohort of irradiated breast cancer patients was $1.8 \%$. Potential risk factors for development of pneumonitis included a mean radiation dose to the ipsilateral lung of $>7 \mathrm{~Gy}$, systemic treatment with taxanes or trastuzumab, chronic inflammatory disease and history of another malignancy.

\section{Conflicts of Interest}

On behalf of all Authors, the corresponding Author states that there are no conflicts of interest related to this study.

\section{Authors' Contributions}

E.M.W., M.C.E., S.B. and D.R. participated in the design of the study. E.M.W., M.C.E., S.B. and D.R. provided data. E.M.W., M.C.E., S.B. and D.R. performed the analyses and the interpretation of the data. D.R. drafted the manuscript, which was reviewed and approved in its final form by all Authors.

\section{Acknowledgements}

Funding: As part of the project NorDigHealth, this study was funded by the European Regional Development Fund through the Interreg Deutschland-Danmark program. 


\section{References}

1 Siegel RL, Miller KD and Jemal A: Cancer statistics, 2019. CA Cancer J Clin 69: 7-34, 2019. PMID: 30620402. DOI: $10.3322 /$ caac. 21551

2 Wenz F and Budach W: Personalized radiotherapy for invasive breast cancer in 2017: National S3 guidelines and DEGRO and AGO recommendations. Strahlenther Onkol 193: 601-603, 2017. PMID: 28631018. DOI: 10.1007/s00066-017-1158-1

3 Vasiljevic D, Arnold C, Neuman D, Fink K, Popovscaia M, Kvitsaridze I, Nevinny-Stickel M, Glatzer M, Lukas P and Seppi $\mathrm{T}$ : Occurrence of pneumonitis following radiotherapy of breast cancer - A prospective study. Strahlenther Onkol 194: 520-532, 2018. PMID: 29450591. DOI: 10.1007/s00066-017-1257-z

4 Epler GR and Kelly EM: Systematic review of postradiotherapy bronchiolitis obliterans organizing pneumonia in women with breast cancer. Oncologist 19: 1216-1226, 2014. PMID: 25361622. DOI: 10.1634/theoncologist.2014-0041

5 Wen G, Tan YT, Lan XW, He ZC, Huang JH, Shi JT, Lin X and Huang XB: New clinical features and dosimetric predictor identification for Symptomatic radiation pneumonitis after tangential irradiation in breast cancer patients. J Cancer 8: 37953802, 2017. PMID: 29151967. DOI: 10.7150/jca.21158

6 Bentzen SM, Constine LS, Deasy JO, Eisbruch A, Jackson A, Marks LB, Ten Haken RK and Yorke ED: Quantitative Analyses of Normal Tissue Effects in the Clinic (QUANTEC): an introduction to the scientific issues. Int J Radiat Oncol Biol Phys 76(3 Suppl): S3-9, 2010. PMID: 20171515. DOI: 10.1016/j.ijrobp. 2009.09.040

7 Oliva D, Nilsson M, Strandéus M, Andersson BÅ, Sharp L, Laytragoon-Lewin $\mathrm{N}$ and Lewin $\mathrm{F}$ : Individual genetic variation might predict acute skin reactions in women undergoing adjuvant breast cancer radiotherapy. Anticancer Res 38: 67636770, 2018. PMID: 30504388. DOI: 10.21873/anticanres.13047

8 Zhou M, Peddi P and Chu QD: Radiation therapy for positive surgical margins in women $\geq 70$ years with stage I, estrogen receptor-positive breast cancer. Anticancer Res 38: 5253-5260, 2018. PMID: 30194175. DOI: 10.21873/anticanres.12850

9 Tuohinen SS, Keski-Pukkila K, Skyttä T, Huhtala H, Virtanen V, Kellokumpu-Lehtinen PL, Raatikainen $\mathrm{P}$ and Nikus K: Radiotherapy-induced early ECG changes and their comparison with echocardiography in patients with early-stage breast cancer. Anticancer Res 38: 2207-2215, 2018. PMID: 29599341. DOI: 10.21873/anticanres.12463

10 Rades D, Panzner A, Janssen S, Dunst J, Veninga T, Holländer $\mathrm{NH}$ and Schild SE: Outcomes after radiotherapy alone for metastatic spinal cord compression in patients with oligometastatic breast cancer. Anticancer Res 38: 6897-6903, 2018. PMID: 30504407. DOI: $10.21873 /$ anticanres.13066

11 Janssen S, Hansen HC, Dziggel L, Schild SE and Rades D: A new instrument for predicting survival of patients with cerebral metastases from breast cancer developed in a homogeneously treated cohort. Radiol Oncol 53: 219-224, 2019. PMID: 31103998. DOI: 10.2478/raon-2019-0020

12 Lohman AC, VAN Rijn I, Lindhardt CL, Vonthein R, Rades D and Holländer NH: Preliminary results from a prospective study comparing white blood cell and neutrophil counts from a laboratory to those measured with a new device in patients with breast cancer. In Vivo 32: 1283-1288, 2018. PMID: 30150458. DOI: $10.21873 /$ invivo.11378
13 Rades D, Dziggel L, Janssen S, Blanck O, Hornung D and Schild SE: A survival score for patients receiving stereotactic radiosurgery alone for brain metastases from breast cancer. Anticancer Res 36: 1073-1076, 2016. PMID: 26977000.

14 Inoue A, Kunitoh H, Sekine I, Sumi M, Tokuuye K and Saijo N: Radiation pneumonitis in lung cancer patients: a retrospective study of risk factors and the long-term prognosis. Int J Radiat Oncol Biol Phys 49: 649-655, 2001. PMID: 11172945. DOI: 10.1016/s0360-3016(00)00783-5

$15 \mathrm{Yu}$ TK, Whitman GJ, Thames HD, Buzdar AU, Strom EA, Perkins GH, Schechter NR, McNeese MD, Kau SW, Thomas ES, Hortobagyi GN and Buchholz TA: Clinically relevant pneumonitis after sequential paclitaxel-based chemotherapy and radiotherapy in breast cancer patients. J Natl Cancer Inst 96: 1676-1681, 2004. PMID: 15547180. DOI: 10.1093/jnci/djh315

16 Taghian AG, Assaad SI, Niemierko A, Kuter I, Younger J, Schoenthaler R, Roche M and Powell SN: Risk of pneumonitis in breast cancer patients treated with radiation therapy and combination chemotherapy with paclitaxel. J Natl Cancer Inst 93: 1806-1811, 2001. PMID: 11734597. DOI: 10.1093/jnci/93.23.1806

17 Bielopolski D, Evron E, Moreh-Rahav O, Landes M, Stemmer SM and Salamon F: Paclitaxel-induced pneumonitis in patients with breast cancer: case series and review of the literature. J Chemother 29: 113-117, 2017. PMID: 25978147. DOI: 10.1179/ 1973947815Y.0000000029

18 Costa R, Costa-Filho RB, Talamantes SM, Queiroga F Jr, Campello EC, Cartaxo H and Costa RB: Interstitial pneumonitis secondary to trastuzumab: A case report and literature review. Case Rep Oncol 10: 524-530, 2017. PMID: 28690527. DOI: $10.1159 / 000477340$

19 Shaw M, Collins BF, Ho LA and Raghu G: Rheumatoid arthritisassociated lung disease. Eur Respir Rev 24: 1-16, 2015. PMID: 25726549. DOI: 10.1183/09059180.00008014

20 Pérez-Dórame R, Mejía M, Mateos-Toledo H and Rojas-Serrano $\mathrm{J}$ : Rheumatoid arthritis-associated interstitial lung disease: lung inflammation evaluated with high resolution computed tomography scan is correlated to rheumatoid arthritis disease activity. Reumatol Clin 11: 12-16, 2015. PMID: 24913966. DOI: 10.1016/j.reuma.2014.02.007

21 Wei Q, Cheng L, Hong WK and Spitz MR: Reduced DNA repair capacity in lung cancer patients. Cancer Res 56: 4103-4107, 1996. PMID: 8797573.

$22 \mathrm{Fu}$ XJ, Shi XJ, Lin K, Lin H, Huang WH, Zhang GJ and Au WW: Environmental and DNA repair risk factors for breast cancer in South China. Int J Hyg Environ Health 218: 313-318, 2015. PMID: 25616561. DOI: 10.1016/j.ijheh.2015.01.001

23 Reiter M, Baumeister P, Jaiser S, Reiss A, Schwenk-Zieger S, Kleinsasser $\mathrm{N}$ and Harréus U: DNA repair and mutagen sensitivity of epithelial cells and lymphocytes in oropharyngeal cancer. Oncol Lett 3: 100-106, 2012. PMID: 22740863. DOI: 10.3892/ol.2011.417

24 Sterpone S, Cornetta T, Padua L, Mastellone V, Giammarino D, Testa A, Tirindelli D, Cozzi R and Donato V: DNA repair capacity and acute radiotherapy adverse effects in Italian breast cancer patients. Mutat Res 684: 43-48, 2010. PMID: 19962393. DOI: $10.1016 /$ j.mrfmmm.2009.11.009

Received September 18, 2019

Revised September 30, 2019 Accepted October 1, 2019 